\title{
Perfil microbiológico del queso de aro consumido en la Cañada Oaxaqueña
} Microbiological profile of aro cheese consumed in Oaxaca, Mexico

Autores | Authors

*Lucio GONZÁLEZ-MONTIEL

Universidad de la Cañada (UNCA) Carr Teotitlán-San Antonio Nanahuatipan Km 1.7, s/n, Paraje Titlacuatitla Caixa Postal: 68540 Teotitlán de Flores Magón/Oax. - México e-mail: luciogonzalez@unca.edu.mx

\section{Melitón Jesús FRANCO-FERNÁNDEZ}

Universidad Autónoma del Estado de Hidalgo (UAEH)

Instituto de Ciencias Agropecuarias (ICAp) Rancho Universitario Tulancingo/Hgo. - Méxcio e-mail: jesusfrancof@hotmail.com

*Autor de correspondencia / Corresponding Author

Recibido: Dic. 12, 2014

Aprobado: Agosto 31, 2015

\section{Resumen}

Se determinó la composición de la microbiota del queso de Aro que se comercializa en el municipio de Teotitlán de Flores Magón, Oaxaca, México. Se cuantificó el contenido de: mesófilos aerobios, psicrófilos, coliformes totales, Escherichia coli, Staphylococcus aureus, Salmonella, Enterococcus, Streptococcus, bacterias ácido lácticas, mohos y levaduras. Los resultados muestran que el queso de Aro contiene microorganismos alterantes, patógenos y de importancia industrial. Ninguna muestra analizada cumple con la NOM-243-SSA1-2010. Por lo tanto, este queso pueden ser un vehículo de transmisión de enfermedades alimentarias, por su elevado contenido de: E. coli, Staphylococcus aureus y Salmonella. La vida de anaquel del queso puede verse afectada provocando pérdidas económicas a los productores. Por otro lado, se pueden obtener microorganismos de importancia industrial (Lactobacillus y Streptococcus). Es necesario implementar sistemas se aseguramiento de la calidad que garanticen la producción de quesos inocuos.

Palabras-clave: Queso fresco; Microorganismos alterantes; Patógenos; Vida de anaquel.

\section{Summary}

The composition of the microbiota of the Aro cheese marketed in the municipality of Teotitlan de Flores Magon, Oaxaca, Mexico, was determined, quantifying the aerobic mesophilic bacteria, psychrophilic bacteria, total coliforms, Escherichia coli, Staphylococcus aureus, Salmonella, Enterococcus, Streptococcus, lactic acid bacteria, moulds and yeasts. The results showed that the Aro cheese contained pathogenic and spoilage microorganisms as well as those of industrial importance. None of the samples analysed complied with NOM-243-SSA1-2010. Thus this cheese could transmit foodborne illnesses, due to its high content of E. coli, Staphylococcus aureus and Salmonella. The shelf life of the cheese could also be affected causing economic losses to the producers. On the other hand, microorganisms of industrial importance can be obtained (Lactobacillus and Streptococcus). It is necessary to implement quality assurance systems to guarantee the production of innocuous cheeses.

Key words: Fresh cheese; Spoilage microorganisms; Pathogens; Shelf life. 


\section{Introducción}

En el mundo se producen cientos de variedades de quesos, algunos autores mencionan que hay entre $400 \mathrm{y}$ 1000 variedades de queso. Sin embargo, existen diversos parámetros empleados para poder clasificar a los quesos, tales como: el tipo de leche (vaca, oveja, cabra, entre otras) o diversas mezclas de estas, el tipo de coagulación (enzimática, láctica o mixta), su textura, el contenido de humedad, la cantidad de extracto seco, la materia grasa, el tipo de microorganismo empleado, la zona geográfica de elaboración o lugar de procedencia, así como el tipo de tecnología usada durante su fabricación (WALSTRA et al., 2006).

En el 2011, México produjo 275.413 toneladas de queso (SIAP, 2012). Siendo el queso fresco el de mayor producción y consumo en México y América Latina, estos quesos se caracterizan principalmente el empleo de leche sin pasteurizar y en muchas ocasiones con procesos no tecnificados (CERVANTES et al., 2006; VILLEGAS et al., 2009; VILLEGAS; CERVANTES, 2011). El queso fresco mexicano se caracteriza por tener un alto contenido de humedad, con sabor suave (a leche), textura suave y cremosa, además de tener una corta vida de anaquel, por lo general, no son quesos madurados y son elaborados con leche entera, leche parcialmente descremada, o leche descremada (NOM, 2010).

La elaboración de quesos en México en las pequeñas y medianas empresas generalmente es muy variable y se encuentra marcada principalmente por aspectos como; las deficientes prácticas de higiene, la poca o nula verificación de la calidad de la materia prima (leche), proceso de fabricación no tecnificado, transporte inadecuado, así como deficiencias al momento de su expendio. Lo anterior podría sugerir que muchos de los quesos que se producen a nivel artesanal pueden contener una gran diversidad de microorganismos de interés sanitario.

El queso de Aro es un queso fresco, de pasta blanda, no prensada, teniendo como presentación la forma de un cilindro de escasa altura. Además, este es uno de los quesos más conocidos en el país. Su elaboración generalmente es con leche cruda de vaca, cabra o una mezcla de ambas (varía en su contenido de materia grasa durante el año). Este tipo de queso presenta escasa estandarización, tanto en materia prima como en su elaboración, así como deficientes prácticas de higiene, poca o nula verificación de la calidad de la materia prima (leche), proceso de fabricación no tecnificado, transporte inadecuado, así como deficiencias al momento de su expendio (CERVANTES et al., 2006; VILLEGAS et al., 2009; DURAN et al., 2010; DOMÍNGUEZ-LÓPEZ et al., 2011; VILLEGAS; CERVANTES, 2011). Por lo antes mencionado, el objetivo de la presente investigación fue determinar la composición de la microbiota de los quesos de Aro de producción artesanal o no tecnificados, que se consumen en Teotitlán de Flores Magón, Oaxaca. Ya que estos pueden contener una gran variedad y cantidad de microorganismos, que pueden catalogarse como; patógenos, alterantes y de interés industrial.

\section{Materiales y métodos}

\subsection{Localización del experimento.}

La fase experimental de la presente investigación se llevó a cabo en las instalaciones del laboratorio de Biología de la Universidad de la Cañada, ubicada en el municipio de Teotitlán de Flores Magón, Oaxaca.

\subsection{Muestras}

En total se adquirieron 12 muestras de queso de Aro (Figura 1), en los meses abril, mayo y junio, ya que en esta época del año se registran las temperaturas más altas de la región $\left(42{ }^{\circ} \mathrm{C}\right.$ aproximadamente, datos obtenidos en la estación meteorológica de la Universidad de la Cañada, Teotitlán de Flores Magón, Oaxaca, México), pudiendo favorecer el desarrollo de microorganismos. Las muestras fueron adquiridas dos horas antes de su análisis, y transportadas a las instalaciones del laboratorio de biología de la Universidad de la Cañada, manteniéndose en refrigeración hasta su análisis. Todas las pruebas microbiológicas se realizaron por duplicado.

\subsection{Determinación de variables microbiológicas}

Preparación de muestras y diluciones. Los procedimientos para la toma, manejo y transporte se realizaron de acuerdo a la NOM-109-SSA1-1994 (NOM, 1994b). La preparación y dilución de las muestras, se llevó a cabo mediante la NOM-110-SSA1-1994 (NOM, 1994C). Se tomó $10 \mathrm{~g}$ de muestra, posteriormente se disolvió en $90 \mathrm{~mL}$ de agua peptonada. La muestra se homogenizó durante un minuto a velocidad media en un Stomacher. Se realizaron las diluciones decimales pertinentes.

Para la cuantificación de mesófilos aerobios y psicrófilos, se utilizó la metodología propuesta en la NOM-092-SSA1-1994 (NOM, 1994a), usando Agar

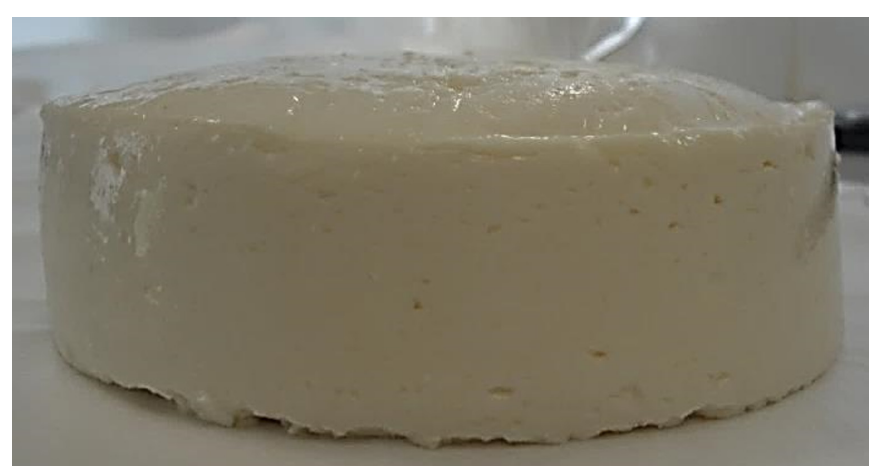

Figura 1. Queso de Aro comercializado en Teotitlán de Flores Magón, Oaxaca, México. 
Métodos Estándar, la incubación fue a $37^{\circ} \mathrm{C} \pm 2^{\circ} \mathrm{C}$ durante $48 \mathrm{~h}$ (mesófilos) y $5^{\circ} \mathrm{C} \pm 2^{\circ} \mathrm{C}$ durante 7 días (psicrófilos). Los hongos filamentosos (mohos) y levaduras se cuantificaron de acuerdo a la NOM-111-SSA1-1994 (NOM, 1994d), utilizando Agar Dextrosa y Papa acidificado con ácido tartárico, los mohos se incubaron a $22{ }^{\circ} \mathrm{C}$ durante 5 días, mientras que las levaduras se incubaron a $22^{\circ} \mathrm{C}$ y $37^{\circ} \mathrm{C}$ durante 48 horas.

La cuantificación de coliformes totales, se realizó de acuerdo a la NOM-113-SSA1-1994 (NOM, 1994e) utilizando Agar Rojo Violeta Bilis Lactosa, la incubación fue a $37^{\circ} \mathrm{C} \pm 2{ }^{\circ} \mathrm{C}$, durante $48 \mathrm{~h}$. Para Escherichia coli, se utilizaron placas deshidratadas Petrifilm. (Petrifilm TM para el recuento de E. coliy Coliformes, 3M Microbiology, Estado Unidos) (AOAC, 2002a). Las placas se incubaron a $37{ }^{\circ} \mathrm{C} \pm 2{ }^{\circ} \mathrm{C}$ durante 48 horas, se consideraron como E. coli, todas aquellas colonias que presentaron una coloración azul acompañadas de producción de gas. Para la cuantificación de Staphylococcus aureus se emplearon dos técnicas; la propuesta por la NOM-115-SSA1-1994 (NOM, 1994g), utilizando Agar base Baird Parker adicionado con emulsión de yema de huevo y telurito de potasio, la siembra fue por superficie y la incubación a $37{ }^{\circ} \mathrm{C} \pm 2{ }^{\circ} \mathrm{C}$, durante $48 \mathrm{~h}$, para la cuantificación se tomaron en cuenta las colonia; redondas, de bordes lisos, convexas, de 2-3 mm de diámetro, húmedos, brillantes, negras con un borde blanco fino, rodeadas de una zona opaca y de un halo claro de 2-5 mm. La otra técnica fue de la AOAC 2001.05, (AOAC, 2002b), utilizando placas deshidratadas Petrifilm TM, (Sistema de Recuento Staph Express, 3M Microbiology, Estado Unidos). Las placas se incubaron a $37^{\circ} \mathrm{C} \pm 2{ }^{\circ} \mathrm{C}$ durante 48 horas. Se consideraron como Staphylococcus aureus a todas aquellas colonias que presentaron una coloración rojo-violeta. La presencia de Salmonella spp, se determinó de acuerdo a la NOM-114-SSA1-1994 (NOM, 1994f). Usando Agua Peptonada estéril en el pre-enriquecimiento, Caldo Tetrationato para el enriquecimiento, adicionado de sales biliares y lugol, para el aislamiento se utilizaron tres medios de cultivo: Agar Mc Conkey, Agar S-S y Agar XLD. La identificación se realizó de acuerdo a las especificaciones de las tablas de identificación de la misma norma, reportando únicamente la presencia o ausencia de Salmonella spp en 25 gramos de muestra. La cuantificación de Enterococcus spp, se realizó de acuerdo Menéndez et al. (2001) usando Agar KF adicionado con TTC al 1\%, la incubación fue a $37^{\circ} \mathrm{C}$ $\pm 2{ }^{\circ} \mathrm{C}$ durante 48 horas.

Para la cuantificación de bacterias ácido lácticas, Lactobacillus spp, se realizó con Agar MRS de acuerdo a De Man et al. (1960). La incubación fue a: $45^{\circ} \mathrm{C} \pm 2{ }^{\circ} \mathrm{C}$ durante $48 \mathrm{~h}, 37^{\circ} \mathrm{C} \pm 2{ }^{\circ} \mathrm{C}$ por $24 \mathrm{~h}$, y $22^{\circ} \mathrm{C} \pm 2{ }^{\circ} \mathrm{C}$ por $72 \mathrm{~h}$. Los Streptococcus spp se cuantificaron de acuerdo a Menéndez et al. (2001) con Agar M17, la incubación fue a: $22^{\circ} \mathrm{C} \pm 2{ }^{\circ} \mathrm{C}$ durante 72 h y a $37^{\circ} \mathrm{C} \pm 2{ }^{\circ} \mathrm{C}$ por 48 horas.

\subsection{Análisis de resultados}

Para conocer la composición de la microbiota presente en el queso de Aro, de cada una de las variables microbiológicas, se determinaron los siguientes valores: media, desviación estándar, valor mínimo, valor máximo y rango, expresados en $\log _{10}$ UFC/g.

\section{Resultados y discusión}

En la Tabla 1, se muestra el recuento de presuntos microorganismos patógenos presentes en el queso de Aro. Este grupo está integrado por: Coliformes totales, Escherichia coli, Staphylococcus aureus, Salmonella spp y Enterococcus spp. El promedio de coliformes totales fue de 6,94 \pm 0,71 $\mathrm{Log}_{10}$ UFC/g. En la NOM-243-SSA1-2010 (NOM, 2010) no se menciona el número máximo permisible de coliformes en quesos frescos, sin embargo nuestros resultados evidencian recuentos muy elevados, y el consumo de este queso podría poner en riesgo la salud del consumidor. Estos resultados coinciden con los reportados por otros autores en muestras de quesos con características similares (GONZÁLEZ et al., 2007; CLAVEL-MAQUEDA, 2006; VÁZQUEZ-FONTES et al., 2008; VÁSQUEZ et al., 2012). Durán-Lengua et al. (2010) reportan 3,4 $\log _{10} \mathrm{NMP} / g$ de coliformes totales en quesos fresco, siendo un indicador de un procesamiento higiénico-sanitario inadecuado. En el queso Oaxaca tradicional, considerando un queso fresco presenta

Tabla 1. Recuento de microorganismos patógenos en queso de Aro que se comercializa en Teotitlán de Flores Magón, Oaxaca. México.

\begin{tabular}{lccccc}
\multicolumn{1}{r}{ Microorganismo } & Media & Desv Est & Min & Máx & Rango \\
\cline { 2 - 6 } & & & Log $_{10}$ UFC/g & & 2,21 \\
Coliformes totales & 6,94 & 0,71 & 5,90 & 7,11 & 1,98 \\
Escherichia coli & 6,74 & 0,73 & 6,00 & 7,49 & 3,49 \\
Staphylococcus aureus & 5,76 & 0,71 & 4,00 & 7,00 & 2,00 \\
Staphylococcus aureus* & 5,98 & 0,65 & 5,00 & 7,71 & 2,41 \\
Enterococcus spp & 6,59 & 0,60 & 5,30 & & \\
Salmonella en 25g & & & Presencia & & \\
\hline
\end{tabular}

${ }^{*}$ Recuento en placa Petrifilm 3M ${ }^{\mathrm{TM}}$ Staph Express. 
un promedio de $9 \log _{10}$ UFC/g de coliformes totales, pudiendo ser un riesgo para la salud del consumidor, por la transmisión de patógenos entéricos (CASTROCASTILLO et al., 2013).

La NOM-243-SSA1-2010 menciona que el número máximo permisible de Escherichia coli en quesos frescos es de 100 UFC/g, ya que una cantidad mayor podría provocar algunas enfermedades gastrointestinales al consumidor. Todas las muestras de queso de Aro analizadas no cumplen con la especificación de la norma, teniendo un mínimo y máximo de 6 y 7,98 $\log _{10}$ UFC/g, respectivamente, con una media de $6,74 \log _{10}$ UFC/g. Estos resultados confirman la evidentemente contaminación de origen fecal, por lo tanto la posible presencia de otros microorganismos de interés sanitario. Silva et al. (2010) analizaron quesos frescos artesanales en los tianguis de Tochtepec, Tecamachalco y Acatzingo, con resultados similares a los nuestros. Por otra parte, Márquez y García (2007) reportan valores similares a los nuestros en queso fresco de Venezuela. Silva et al. (2006) mencionan que algunos quesos frescos de Brasil presentan conteos muy elevados de E. coli, siendo estos no aptos para consumo humano, ya que la presencia de E coli indica una contaminación fecal. El queso fresco artesanal de municipio de san José Tuzuapan, Puebla, México, presenta una elevada carga bacteriana por deficiencias higiénicas en su elaboración y distribución (RESÉNDIZ et al., 2012).

La cantidad de Staphylococcus aureus por método tradicional fue de 5,76 0,71 $\log _{10}$ UFC/g, y en placa Petrifilm fue de 5,98 $\pm 0,65 \log _{10}$ UFC/g. Dichos conteos son superiores a los permitidos por la Secretaría de Salud, debido a que el número máximo permisible de Staphylococcus aureus en quesos frescos es de $3 \log _{10}$ UFC/g NOM-243-SSA1-2010 (NOM, 2010). Cabe hacer mención, que los resultados no muestran diferencia significativa en la cuantificación por método tradicional o placa Petrifilm. El queso fresco comercializado en Venezuela presenta un promedio de 5,53 $\log _{10}$ UFC/g, debido un proceso de producción sin control de prácticas de higiene (MALDONADO; GARCÍA, 2010). Castro-Castillo et al. (2013) mencionan que un elevando contenido de Staphylococcus en quesos fresco indica serias fallas en las condiciones higiénico-sanitarias de las queserías, debido a las malas prácticas de manipulación en el ordeño, recolección y transporte de leche, refrigeración inadecuada o falta de ella en la leche y queso. En consecuencia, su consumo representa un peligro latente para el consumidor, pudiendo provocar una intoxicación estafilocócica (MALDONADO; GARCÍA, 2010; RESTREPO; MONTOYA, 2010).

Las muestras presentaron un máximo de 7,71 $\log _{10}$ UFC/g y un mínimo de 5,30 $\mathrm{Log}_{10}$ UFC/g de Enterococcus spp, con un promedio 6,59 $\log _{10}$ UFC/g. Sin embargo, frecuentemente se pueden aislar Enterococcus en alimentos, especialmente en productos lácteos, éstos poseen características vinculadas con patologías humanas o animales. Se ha observado que cepas de enterococos aisladas de alimentos o del medio ambiente poseen factores de virulencia, que se creían restringidos a las cepas aisladas de humanos o ambientes relacionados con actividades humanas (DELPECH, 2013). Por otro lado, en la actualidad no ha sido posible establecer una correlación entre la ingesta de alimentos que contienen enterococos e infecciones de origen alimentario. Sin embargo, los productos lácteos pueden constituir reservorios de cepas que exhiben genes vinculados con factores de virulencia que podrían ser transferidos a cepas humanas en el tracto gastrointestinal (MARGUET et al., 2008).

Todas las muestras del queso de Aro presentaron colonias típicas del género Salmonella spp, esto de acuerdo a la NOM-114-SSA1-1994 (NOM, 1994g). Cabe hacer mención, que la salmonelosis es una de las enfermedades más importantes y que en los últimos años los quesos se han visto involucrados en diversos brotes de enfermedades alimentarias (PEÑA et al., 2011). Diversos brotes de salmonelosis debidos al consumo de quesos contaminados han sido atribuidos a una falta de control durante el proceso de elaboración, o la utilización de leche cruda contaminada (ALERTE et al., 2012).

En la Tabla 2, se muestran los recuentos de los microorganismos alterantes presentes en el queso de Aro. Este grupo está integrado por: mesófilos aerobios, psicrófilos, mohos y levaduras. La media de los distintos grupos de microorganismos fueron expresado en $\log _{10}$ UFC/g; mesófilos aerobios 8,14 \pm 0,48, psicrófilos $8,07 \pm 0,7$, mohos $2,97 \pm 0,63$, levaduras a $35^{\circ} \mathrm{C}$ $3,59 \pm 0,71$ y levaduras a $22{ }^{\circ} \mathrm{C} 4,83 \pm 0,67$

Tabla 2. Recuento de microorganismos alterantes ( $\left.\log _{10} \mathrm{UFC} / \mathrm{g}\right)$ en queso de Aro.

\begin{tabular}{lccccc}
\multicolumn{1}{c}{ Microorganismo } & Media & Desv. Est & Min & Máx & Rango \\
\cline { 2 - 6 } & & & Log $_{\mathbf{1 0}}$ UFC/g & & \\
Mesófilos aerobios & 8,14 & 0,48 & 7,37 & 9,30 & 1,93 \\
Psicrófilos & 8,07 & 0,70 & 6,70 & 9,00 & 2,30 \\
Mohos $22^{\circ} \mathrm{C}$ & 2,97 & 0,63 & 2,00 & 4,08 & 2,08 \\
Levaduras $35^{\circ} \mathrm{C}$ & 3,59 & 0,71 & 2,00 & 5,00 & 3,00 \\
Levaduras $22^{\circ} \mathrm{C}$ & 4,83 & 0,67 & 3,85 & 6,04 & 2,19 \\
\hline
\end{tabular}


El recuento máximo de mesófilos aerobios fue de 9,30 $\log _{10}$ UFC/g y un mínimo de 7,37 $\log _{10}$ UFC/g. Estos resultados son muy elevados, ya que no se utilizan cultivos iniciadores para la elaboración de este tipo de queso. En México, la Secretaría de Salud, en la NOM-243-SSA1-2010 (NOM, 2010), no especifica la cantidad máxima permisible de mesófilos aerobios en quesos frescos frescales. Sin embargo, aun cuando estos microorganismos no sean conocidos como patógenos y no hayan alterado de forma apreciable los caracteres organolépticos de los quesos, su cuantificación e identificación es justificable por varias razones: 1) Recuentos altos pueden indicar almacenamiento inadecuado (tiempo/temperatura), 2) Puede existir la presencia de microorganismos patógenos, ya que todas las bacterias patógenas conocidas transmitidas vía alimentaria son mesófilas y algunas cepas bacterianas son patógenos oportunistas, 3) Muchos de estos microorganismos son los responsables de las modificaciones organolépticas de los alimentos (MALDONADO; GARCíA, 2010). Vásquez et al. (2012) reportan conteos similares a los nuestros en queso blanco, indicando malas prácticas de manufactura y, por consiguiente, un riesgo para la salud del consumidor. Renye et al. (2008) reportan valores de 8,89 y $8,97 \log _{10}$ UFC/g en muestras de queso fresco tipo hispano elaborado con leche sin pasteurizar y con leche pasteurizada.

Respecto al contenido de psicrófilos, se cuantificó una media de 8,07 $\pm 0,70 \log _{10}$ UFC/g en queso de Aro (Tabla 2). Entre los géneros de bacterias psicrófilas de mayor importancia en quesos encontramos a: Pseudomonas spp., Alcaligenes spp., Achromobacter spp. y Flavobacteriurn spp. Todas ellas son fácilmente destruidas durante la pasteurización y/o temperatura de cocción de algunos quesos, su presencia indica una contaminación post-fabricación. La cuantificación de estos microorganismos es importante, ya que producen enzimas proteolíticas y lipolíticas muy activas, provocando cambios en las propiedades organolépticas del queso, tales como: amargo, rancio y putrefacto, superficie viscosa, decoloración debido a la hidrolisis de la caseína, causando oscurecimiento y cambio a color amarillo en la superficie (FARKYE; VEDAMUTHU, 2002).
El contenido de hongos en las muestras de queso de Aro fue el siguiente: hongos filamentosos (mohos) promedio de 2,97 $\pm 0,63 \log _{10}$ UFC/g, con un mínimo de 2,0 y un máximo de $4,08 \mathrm{Log}_{10} \mathrm{UFC} / \mathrm{g}$, levaduras a $22^{\circ} \mathrm{C}$ con un promedio de 4,83 \pm 0,67 $\log _{10} \mathrm{UFC/g}$, con un mínimo de 3,85 y un máximo de 6,04 $\log _{10}$ UFC/g y levaduras a $35^{\circ} \mathrm{C}$ con un promedio de $3,59 \pm 0,71 \log _{10} \mathrm{UFC} / \mathrm{g}$, con un mínimo de 2 y un máximo de $5 \log _{10}$ UFC/g. Cabe hacer mención, que no existe diferencia en el contenido de levaduras a $22{ }^{\circ} \mathrm{C}$ como a $35^{\circ} \mathrm{C}$. Estos resultados son superiores al máximo permisible por Secretaría de Salud, que es de 500 UFC/g (NOM, 2010). Jiménez-Vera et al. (2010) reportan conteos superiores a $6 \log _{10}$ UFC/g de mohos y levaduras en quesos artesanales. Granados et al. (2010) mencionan que la presencia de hongos en queso fresco se debe a que el ambiente de trabajo, los equipos, utensilios y el almacenamiento presentan deficiencias higiénicas. Castro-Castillo et al. (2013) mencionan que las levaduras actúan como contaminantes en productos lácteos ya están presentes en la leche y las condiciones de procesamiento favorecen su desarrollo, pudiendo causar alteraciones en los quesos, siendo los defectos más comunes; el sabor mohoso, cambios en la textura, la excesiva formación de gas (hinchazón de quesos), el aumento de la acidez debido a los efectos estimulantes sobre las bacterias ácido lácticas, así como la decoloración y crecimiento superficial. Por último, algunos autores consideran que las levaduras no producen enfermedades transmitidas por alimentos (ETA), pero pueden causar deterioro en el producto.

En la Tabla 3, se muestra el recuento de bacterias lácticas presentes en muestras de queso de Aro, integrado principalmente por Lactobacillus y Streptococcus a diversas temperaturas de crecimiento. El promedio de los Lactobacillus a $22^{\circ} \mathrm{C}$ fue de $8,27 \pm 0,48 \mathrm{Log}_{10} \mathrm{UFC} / \mathrm{g}$, a $35^{\circ} \mathrm{C}$ fue de $8,13 \pm 0,34 \log _{10}$ UFC/g y a $45^{\circ} \mathrm{C}$ fue de 7,47 $\pm 0,52 \log _{10}$ UFC/g. Para los Streptococcus el promedio a $22{ }^{\circ} \mathrm{C}$ fue de $8,35 \pm 0,53$ y a $35{ }^{\circ} \mathrm{C}$ de $8,15 \pm 0,47 \log _{10}$ UFC/g

Como ya se ha mencionado, el queso de Aro es un queso fresco frescal de coagulación netamente enzimática, por lo que no se esperaría que tuviera recuentos muy elevados de bacterias ácido lácticas,

Tabla 3. Contenido de bacterias ácido lácticas en queso de Aro $\left(\log _{10}\right.$ UFC/g).

\begin{tabular}{|c|c|c|c|c|c|}
\hline \multirow{2}{*}{ Microorganismo } & Media & Desv. Est & Min & Máx & Rango \\
\hline & \multicolumn{5}{|c|}{$\log _{10}$ UFC/g } \\
\hline Lactobacillus $35^{\circ} \mathrm{C}$ & 8,13 & 0,34 & 7,30 & 9,15 & 1,85 \\
\hline Lactobacillus $22^{\circ} \mathrm{C}$ & 8,27 & 0,48 & 7,00 & 9,14 & 2,14 \\
\hline Lactobacillus $45^{\circ} \mathrm{C}$ & 7,47 & 0,52 & 6,48 & 8,32 & 1,85 \\
\hline Streptococus $22^{\circ} \mathrm{C}$ & 8,35 & 0,53 & 7,70 & 9,77 & 2,07 \\
\hline Streptococus $35^{\circ} \mathrm{C}$ & 8,15 & 0,47 & 7,00 & 9,32 & 2,32 \\
\hline
\end{tabular}


teniendo en promedio $8 \log _{10}$ UFC/g. La presencia de este tipo de bacterias en quesos frescos se puede atribuir principalmente al proceso de elaboración, así como a la forma de conservar. También podría atribuirse a la forma en cómo este queso es transportado y conservado en el punto de venta. Cabe hacer alusión, que la mayoría de las bacterias ácido lácticas crecen bien en temperatura de refrigeración (AXELSSON, 1998). Muchos investigadores concuerdan que las bacterias ácido lácticas ejercen un efecto inhibitorio contra patógenos, sin embargo en este trabajo no se pudo apreciar dicha relación, ya que los recuentos de presuntos patógenos fue elevados, esto debido a que el queso de Aro es un queso fresco y el efecto inhibitorio se aprecia principlamnete en quesos madurados. Los factores que producen inhibición de patógenos por parte de las bacterias ácido lácticas tenemos, la producción de $\mathrm{H}_{2} \mathrm{O}_{2}$, generación de ácidos orgánicos, producción de bacteriocinas, entre otras (PARRA-HUERTAS, 2010). Galinari et al. (2014) obtuvieron un promedio igual al nuestro en quesos artesanales de Brasil. Pogačić et al. (2010) mencionan que Lactococcus lactis es la bacteria ácido láctica predominante en queso artesanal elaborado con leche de oveja del este de Croacia. Clavel-Maqueda (2006) reporta un promedio de 6,02 $\log _{10}$ UFC/g en muestras de queso Panela, de igual forma menciona que en este tipo de muestras los conteos son muy elevados y podrían afectar la vida de anaquel del producto, provocando un sabor ácido.

\section{Conclusiones}

El queso de Aro que se comercializan en el municipio de Teotitlán de Flores Magón, Oaxaca, presenta una mala calidad microbiológica, teniendo un elevado contenido de microorganismos, compuesta principalmente por microorganismos; alterantes, presuntos patógenos, y algunos de importancia industrial.

El recuento de microorganismos indicadores de contaminación fecal es elevado, superando los límites establecidos por Secretaría de Salud y la presencia de indicadores de contaminación fecal, puede sugerir la presencia de algunos patógenos. Por lo tanto, es posible que el consumo de estos quesos, afecten la salud de consumidor, provocando principalmente enfermedades gastrointestinales. Además, la vida de anaquel puede verse afectada, ya que existe una gran cantidad de microorganismos alterantes.

El queso de Aro puede ser una excelente fuente para el aislamiento, purificación e identificación de microorganismos de importancia industrial, por ejemplo, para la obtención de bacterias probióticas.

\section{Referencias}

ALERTE, V.; CORTÉS, A. S.; DÍAZ, T. J.; VOLLAIRE, Z. J.; ESPINOZA, M. M. E.; SOLARI, G. V.; CERDA, L. J.; TORRES, H.
M. Brotes de enfermedades transmitidas por alimentos y agua en la Región Metropolitana, Chile (2005-2010). Revista Chilena de Infectologia, Santiago, v. 29, n. 1, p. 26-31, 2012. http://dx. doi. org/10.4067/S0716-10182012000100004. PMid:22552507.

ASSOCIATION OF OFFICIAL AGRICULTURAL CHEMISTS AOAC. Official Method 991.14. Coliform and Escherichia coli count in foods, dry rehydratable film. Gaithersburg, 2002a.

ASSOCIATION OF OFFICIAL AGRICULTURAL CHEMISTS - AOAC. Official Method 2001.05. PetrifilmTM Rapid S. aureus count plate method for the rapid enumeration of Staphylococcus aureus in selected foods. Gaithersburg, 2002b.

AXELSSON, L. T. Lactic acid bacteria: classification and physiology. In: SALMINEN, S.; VON WRIGHT, A. Lactic acid bacteria, microbiology and functional aspects. 2 nd. ed. New York: Marcel Dekker, Inc, 1998. Chapter 1, p. 1-72.

CASTRO-CASTILLO, G.; MARTÍNEZ-CASTAÑEDA, F. E.; MARTÍNEZ-CAMPOS, A. R.; ESPINOZA-ORTEGA, A. Caracterización de la microbiota nativa del queso Oaxaca tradicional en tres fases de elaboración. Revista de la Sociedad Venezolana de Microbiología, Caracas, v. 33, p. 105-109, 2013.

CERVANTES, E. F.; VILLEGAS, G. A.; VARGAS, C. A.; ORTEGA, A. E. Los quesos mexicanos genuinos: un saber hacer que se debe rescatar y preservar. In: CONGRESO INTERNACIONAL DE LA RED SIAL "ALIMENTACIÓN Y TERRITORIOS", 3., 2006, Baeza. Anales... Paris: SYAL ERG, 2006. p. 1-38.

CLAVEL-MAQUEDA, M. Condiciones microbiológicas y aislamiento de bacterias lácticas en quesos artesanales del estado de Hidalgo. 2006. 92 p. Tesis (Químico en Alimentos)Instituto de Ciencias Básicas e Ingeniería, Universidad Autónoma de Hidalgo, Pachuca, 2006.

DE MAN, J. D.; ROGOSA, M.; SHARPE, M. E. A medium for the cultivation of Lactobacilli. The Journal of Applied Bacteriology, Oxford, v. 23, n. 1, p. 130-135, 1960. http://dx. doi. org/10.1111/j.1365-2672.1960.tb00188.x.

$\mathrm{DELPECH}, \mathrm{G}$. Caracterización de especies y perfil de resistencia antimicrobiana en enterococos aislados de alimentos de origen animal provenientes de un área rural del Centro de la Provincia de Buenos Aires, Argentina. 2013. 179 p. Tesis (Doctoral)- Facultad de Ciencias Médicas, Universidad Nacional de la Plata, Argentina, 2013.

DOMÍNGUEZ-LÓPEZ, A.; VILLANUEVA-CARVAJAL, A.; ARRIAGA-JORDÁN, C.; ESPINOZA-ORTEGA, A. Alimentos artesanales y tradicionales: el queso Oaxaca como un caso de estudio del centro de México. Artisan-made and traditional foods: The Oaxaca fresh cheese as study case in central Mexico. Estudios Sociales, Santo Domingo, v. 19, p. 166-193, 2011.

DURAN, L.; SÁNCHEZ, C.; PALMERO, J.; CHAPARRO, L.; GARCÍA, T.; SÁNCHEZ, E. Caracterización fisicoquímica y microbiológica de quesos de cabra en Carora, estado Lara, 
Venezuela. Zootecnia Tropical, Maracay, v. 28, n. 4, p. 467-475, 2010.

DURÁN-LENGUA, M.; MONTERO-CASTILLO, P.; FLÓREZDÍAZ, W.; FRANCO DE LA HOZ, V.; CONEO-RODRÍGUEZ, R. Evaluación higiénico-sanitaria y acción antagónica de cepas de lactobacilos comerciales frente a microorganismos patógenos (Escherichia coli) presentes en el queso de Capa del municipio de Mompox. Revista Científica FCV-LUZ, Maracaibo, v. 20, n. 3, p. 312-317, 2010.

FARKYE, N. Y.; VEDAMUTHU, E. R. Microbiology of soft cheeses. In: ROBINSON, R. K. (Ed.). Dairy microbiology handbook: the microbiology of milk and milk products. 3rd. ed. New York: Jonhn Wiley \& Sons, 2002. Chapter 10, p. 479-514.

GALINARI, É.; NÓBREGA, J. E.; ANDRADE, N. J.; FERREIRA, C. L. L. F. Microbiological aspects of the biofilm on wooden utensils used to make a brazilian artisanal cheese. Brazilian Journal of Microbiology, São Paulo, v. 45, n. 2, p. 713-720, 2014. http://dx.doi.org/10.1590/S1517-83822014000200047. PMid:25242963

GONZÁleZ, C. U. D.; PÉREZ, V. V. J.; CLEMENTE, C. A.; MAZARIEGOS, E. M. A.; RUIZ, T. M. J.; RODRÍGUEZ, F. M. A. Determinación de coliformes totales en los productos lácteos y su comparación entre dos queserías del municipio de Pijijiapan, Chiapas, México. Bioquímica, Mexico, v. 32, p. 98, 2007.

GRANADOS, C.; URBINA, O. G.; DIOFANOR, A. C. Tecnificación, caracterización fisicoquímica y microbiológica del queso de capa de Mompox Colombia. Facultada de Ciencias Agropeciarias, Mendoza, v. 8, n. 2, p. 41-45, 2010.

JIMÉNEZ-VERA, R.; GONZÁlEZ, C. N.; MAGAÑA, C. A.; LIZCANO, C. A.; CABRERA, P. E. Aislamiento de bacterias lácticas y levaduras de queso Poro artesanal. In. CONGRESO NACIONAL DE CIENCIA Y TECNOLOGÍA DE ALIMENTOS, 12., 2010, Guanajuato. Anales... León: Universidade de Guanajuato, 2010. p. LA71-LA714.

MALDONADO, R.; GARCÍA, D. Caracterización físico química y microbiológica del queso blanco artesanal tipo Llanero comercializado en la ciudad Maracay, Estado de Aragua. Agrollania, Cojedes, v. 7, p. 118-126, 2010.

MARGUET, E. R.; VALLEJO, M.; OLIVERA, N. L. Factores de virulencia de cepas de Enterococcus aisladas de quesos ovinos. Acta Bioquímica Clínica Latinoamericana, v. 42, n. 4, p. 543-548, 2008.

MÁRQUEZ, J. G.; GARCÍA, R. C. E. Microflora patógena del queso blanco "Telita" elaborado en cuatro estados de Venezuela. Anales Venezolanos de Nutrición, v. 20, n. 1, p. 17-21, 2007.

MENÉNDEZ, S.; GODÍNEZ, R.; CENTENO, J. A.; RODRÍGUEZOTERO, J. L. Microbiological, chemicals and biochemical characteristics of Telita raw cows-milk cheese. Food Microbiology. International Dairy Journal, Summit-Argo, v. 18, n. 2, p. 151-158, 2001. http://dx. doi.org/10.1006/fmic.2000.0385.
NORMA OFICIAL MEXICANA - NOM. NOM-092-SSA1-1994: bienes y servicios. Método para la cuenta de bacterias aerobias en placa. México, D.F., 1994a.

NORMA OFICIAL MEXICANA - NOM. NOM-109-SSA1-1994: bienes y servicios. Procedimientos para la toma, manejo y transporte de muestras de alimentos para su análisis microbiológico. México, D.F., 1994b.

NORMA OFICIAL MEXICANA - NOM. NOM-110-SSA1-1994: bienes y servicios. Preparación y dilución de muestras de alimentos para su análisis microbiológico. México, D.F., 1994c.

NORMA OFICIAL MEXICANA - NOM. NOM-111-SSA1-1994: bienes y servicios. Método para la cuenta de mohos y levaduras en alimentos. México, D.F., 1994d.

NORMA OFICIAL MEXICANA - NOM. NOM-113-SSA1-1994: bienes y servicios. Método para la cuenta de microorganismos coliformes totales en placa. México, D.F., 1994e.

NORMA OFICIAL MEXICANA - NOM. NOM-114-SSA1-1994: bienes y servicios. Método para la determinación de Salmonella en alimentos. México, D.F., $1994 f$.

NORMA OFICIAL MEXICANA - NOM. NOM-115-SSA1-1994: bienes y servicios. Método para la determinación de Staphylococcus aureus en alimentos. México, D.F., 1994g.

NORMA OFICIAL MEXICANA - NOM. NOM-243-SSA1-2010: leche, fórmula láctea, producto lácteo combinado y derivados lácteos. Disposiciones y especificaciones sanitarias. Métodos de prueba. México, D.F., 2010.

PARRA-HUERTAS, R. A. Review. Bacterias ácido lácticas: papel funcional en los alimentos. Facultad de Ciencias Agropecuarias, Mendoza, v. 8, n. 1, p. 93-105, 2010.

PEÑA, Y. P.; HERNÁNDEZ, M. E.; CASTILLO, V. L.; LÓPEZ, N. A.; DÍAZ, M. M.; RODRÍGUEZ, P. S. Serovariedades y patrones de susceptibilidad a los antimicrobianos de cepas de Salmonella aisladas de alimentos en Cuba. Revista Panamericana de Salud Pública, Washington, v. 30, n. 6, p. 561-565, 2011. http://dx.doi. org/10.1590/S1020-49892011001200011. PMid:22358403.

POGAČIĆ, T.; SAMARŽIJA, D.; CORICH, V.; D'ANDREA, M.; KAGKLI, D. M.; GIACOMINI, A.; ČANŽEK MAJHENIČ, A.; ROGELJ, I. Microbiota of Karakačanski skakutanac, an artisanal fresh sheep cheese studied by cultureindependent PCR-ARDRA and PCR-DGGE. Dairy Science \& Technolonology, Dordrecht, v. 90 , n. 4 , p. 461-468, 2010. http://dx.doi.org/10.1051/ dst/2010004

RENYE, J. A.; SOMKUTI, G. A.; VALLEJO-CORDOBA, B.; VAN HEKKEN, D. L.; GONZALEZ-CORDOVA, A. F. Characterization of the microflora isolated from queso fresco made from raw and pasteurized milk. Journal of Food Safety, Westport, v. 28 , n. 1, p. 59-75, 2008. http://dx.doi.org/10.1111/j.17454565.2007.00095.x. 
RESÉNDIZ, M. R.; HERNÁNDEZ, Z. J. S.; RAMíREZ, H. R.; PÉREZ, A. R. El queso fresco artesanal de la canasta básica y su calidad sanitaria en Tuzuapan, México. Actas Iberoamericanas de Conservación Animal, Córdoba, v. 2, p. 253-255, 2012.

RESTREPO, A. A. F.; MONTOYA, G. C. A. Implementación y diseño de procedimiento para determinación de vida útil de quesos frescos, chorizos frescos y agua en bolsas. 2010. 73 p. Tesis (Tecnólogo Químico)-Facultad de Tecnologías, Universidad Tecnológica de Pereira, Colombia, 2010.

SERVICIO DE INFORMACIÓN AGROALIMENTARIA Y PESCA - SIAP. Boletin de leche. 2012. Disponible en: <http:// www.siap.gob.mx/wp-content/uploads/2013/BoletinLeche/ Lecheenemar2012.pdf>. Acceso en: 19 nov. 2014.

SILVA, G. S. E.; RESÉNDIZ, M. R.; HERNÁNDEZ, Z. J. S.; PÉREZ, A. R.; PÉREZ, B. J. El queso fresco artesanal de vaca: calidad bacteriológica. In. SIMPOSIO IBEROAMERICANO SOBRE CONSERVACIÓN Y UTILIZACIÓN DE RECURSOS ZOOGENÉTICOS, 11., 2010, Joao Pessoa. Anales... Campina Grande: Instituto Nacional do Semiárido, 2010.

SILVA, M. P.; CAVALLI, D. R.; OLIVEIRA, T. C. R. M. Avaliação do padrão coliformes a $45^{\circ} \mathrm{C}$ e comparação da eficiência das técnicas dos tubos múltiplos e Petrifilm ec na detecção de coliformes totais e Escherichia coli em alimentos. Ciência e Tecnologia de Alimentos, Campinas, v. 26, n. 2, p. 352-359, 2006. http://dx.doi.org/10.1590/S0101-20612006000200018.

VÁSQUEZ, N.; DURÁN, L.; SÁNCHEZ, C.; ACEVEDO, I. Evaluación de las características fisicoquímicas y microbiológicas del queso blanco a nivel de distribuidores, estado Lara, Venezuela. Zootecnia Tropical, Maracay, v. 30, n. 3, p. 217-223, 2012.

VÁZQUEZ-FONTES, C.; SÁNCHEZ-VERA, E.; CASTELÁNORTEGA, O.; ESPINOZA-ORTEGA, A. Microbiological quality of artisan-made Mexican Botanero cheese in the central highlands. Journal of Food Safety, Westport, v. 30, n. 1, p. 40-50, 2008. http://dx.doi.org/10.1111/j.1745-4565.2009.00188.x.

VILLEGAS, A.; SANTOS, M. A.; HERNÁNDEZ, A. Los quesos mexicanos genuinos: contribución a su rescate a través de la vinculación Universidad-Productores. Claridades Agropecuarias, México, D.F., v. 191, p. 29-35, 2009.

VILLEGAS, G. A.; CERVANTES, E. F. La genuinidad y tipicidad en la revalorización de los quesos artesanales mexicanos. Estudios Sociales, Santo Domingo, v. 19, n. 38, p. 145-164, 2011.

WALSTRA, P.; WOUTERS, J. T. M.; GEURTS, T. J. Dairy science and technology. 2nd. ed. New York: Taylor \& Francis, 2006. p. 687-698. 